\title{
Operationalizing a Framework for Assessing the Enabling Environment for Community Forest Enterprises: A Case Study from Nepal
}

\author{
Bishnu Prasad Sharma ${ }^{1}$. Steven Lawry ${ }^{2}$. Naya Sharma Paudel ${ }^{3}$. \\ Rebecca McLain ${ }^{2}$ D . Anukram Adhikary ${ }^{3}$. Mani Ram Banjade ${ }^{2}$
}

Accepted: 19 January 2020 / Published online: 27 January 2020

(c) The Author(s) 2020

\begin{abstract}
We demonstrate how Baynes et al.'s (Glob Environ Change 35:226-238, 2015. https ://doi.org/10.1016/j.gloenvcha.2015.09.011) framework can be operationalized as a tool for identifying potential intervention points for supporting the tenure and governance-enabling environment for CFEs. We do so by applying the framework to a sample of CFUG-managed CFEs in Nepal to see how they measure up as a group with respect to the five success factors. Our study suggests that for CFEs to thrive, they will require policy and legal frameworks that devolve commercial harvesting rights to economically valuable products, and provision of processing locations and licensing practices that are not overly restrictive. The findings will be useful not only for Nepal, but for many other countries dependent on forests for their economic development and whose inhabitants rely on forests for their livelihoods.
\end{abstract}

Keywords Forest enterprises $\cdot$ Community-based forest management $\cdot$ Rights devolution $\cdot$ Forest investment

\footnotetext{
An early version of this article was presented at the 2017 World Bank Conference on Land and Poverty (Sharma et al. 2017).
}

Electronic supplementary material The online version of this article (https://doi.org/10.1007/s1184 2-020-09433-w) contains supplementary material, which is available to authorized users.

Rebecca McLain

rebecca.mclain@gmail.com

1 Patan Multiple Campus, Tribhuvan University, Kirtipur, Nepal

2 Center for International Forestry Research, Bogor, Indonesia

3 ForestAction, Patan, Nepal 


\section{Introduction}

Over the past 3 decades, a trend toward devolving forest rights to indigenous peoples, communities, individuals, households, and firms has emerged in developing countries (Larson and Dahal 2012). Attention has focused on supporting community forest enterprises (CFEs) so that forest dwellers can capture a greater share of the value of products harvested from community-managed forests (Antinori and Bray 2005; Bray et al. 2006). Yet in many countries, forest devolution benefits have proved illusory, with governments tending to devolve subsistence use rights while reserving more economically lucrative rights or encumbering the exercise of commercial activities with heavy regulatory requirements (Ribot et al. 2010). Consequently, the ability of CFEs and rural households to prosper from newly acquired or recognized forest rights has often been less than expected.

Nepal was among the earliest countries to adopt forest rights devolution on a national scale. Historically, forest rights were vested in the state, and district-level forest agencies regulated most uses of forested land and products. This began to change in the 1970s, when Nepal embarked on a national initiative to devolve forest rights to forest-dependent communities. Reforms were consolidated during the 1990s, when significant forest use and management rights were granted to Community Forest User Groups (CFUGs). Many argued that forest users would have a greater incentive to sustainably use forests if they could benefit from conservation investments. Forest cover has improved markedly in many areas under CFUG control (MFSC 2013; DFRS 2015; Gurung et al. 2013).

Based on a comparative analysis of 45 community forest case studies in Nepal, Mexico, and the Philippines, Baynes et al. (2015) identified five success factors for community-based forestry: (1) a reduction in socio-economic status and genderbased inequality, (2); secure tree and land rights, (3); transparent and equitable intra-community forest group governance, (4); government support, and (5); provision of material benefits to community members. In this paper, we demonstrate how Baynes et al.'s (2015) framework can be operationalized as a tool for identifying intervention points for supporting the tenure and governance-enabling environment for CFEs. We apply the framework to a sample of CFUG-managed CFEs in Nepal to see how they measure up with respect to the five success factors. Our study suggests steps for enhancing the legal and policy conditions needed for CFEs to thrive. The findings will be useful for many countries whose inhabitants rely on forests for their livelihoods.

\section{The Nepalese Context}

Nepal suffered heavy deforestation following the implementation of the 1957 Private Forest Nationalization Act, which ended the traditional rights of communities over forests. The 1976 National Forestry Plan and the 1978 Forest Rules handed forests back to communities to address resource degradation created by government control over the forests. The 1993 Forest Act and the 1995 Forest Regulations furthered 
forest tenure devolution through widespread conversion of government-managed forests to community-managed forests through CFUGs (Acharya 2002). Since then, communities have invested in forest management activities, such as thinning and pruning, guarding against illegal felling, and controlling forest fires. Approximately 20,000 CFUGs manage around 30\% of Nepal's forest area (CBS 2011; MOF 2016). Improved forest quality and greater availability of timber, firewood, fodder, and several commercialized non-timber forest products (NTFPs) are evidence of their success (Chand et al. 2015; Pandit and Bevilacqua 2011).

As the ecological condition of their forests has improved, Nepalese communities have established CFEs, such as sawmills and essential oil extractors, that use local forest products or tourism activities that use local forests as a draw for ecotourists. The goals of these enterprises are to provide employment, reduce poverty, and meet other social development goals set by the community forestry program (MFSC 2009). Subedi et al. (2014) estimated that about 40,000 forest-based enterprises existed in Nepal, of which $66 \%$ were primary producers and $34 \%$ were involved in value addition through processing, manufacturing, and trade. CFUG-managed enterprises were found in both categories. These CFEs have attracted investments from CFUG funds, individual members, and donor agencies. However, many enterprises fail once external financing ceases (Koirala et al. 2013), and limited administrative and technical capacity of communities combined with burdensome regulations limits their ability to generate local employment and economic growth (Kunwar et al. 2009; Banjade et al. 2017). To identify areas for improvement, there is a need for a tool to assess whether the elements of a positive enabling environment are present for CFEs.

\section{Literature Review}

A large literature examines factors influencing the success of forest-based enterprises (Albano et al. 2008; Lamsal et al. 2017; Sanchez-Bandini et al. 2018). Studies of CFEs in Mexico identify agrarian reform and tenure rights devolution, along with supporting factors such as intermittent legislative and programmatic support, as contributing to the widespread emergence of successful CFEs in Mexico (Cubbage et al. 2015; Antinori and Bray 2005; Bray et al. 2006). Tenure rights devolution is considered a prerequisite for communities to mobilize and improve natural resource management, which in turn, may lead to livelihood improvement (Antinori and Bray 2005; Bray et al. 2006). Dhungana and Bhattarai's (2008) study of Nepalese CFEs found that timber processing constituted the greatest value addition from the forestry sector. They concluded that forest management oriented toward subsistence and focused only on locally available NTFPs was rarely conducive to forest-based enterprise development. However, even when commercial rights are devolved, the extremely cumbersome procedures for securing harvesting permits and registering enterprises may limit the scope of CFEs to provide meaningful returns to investment (Baynes et al. 2016; Kunwar et al. 2009; Persson and Prowse 2017). Macqueen (2008) identified lack of connectedness as the central 
problem of forest-based enterprises: they are often isolated from the market, financial services, and business development services.

These studies underscore the importance of a positive tenure and governance-enabling environment for CFE emergence and long-term success. However, a diagnostic tool is lacking for assessing whether a positive enabling environment for CFEs exists and identifying intervention points for improving the likelihood of CFE success. To develop such a tool, we drew on Baynes et al.'s (2015) research on factors that appear to be necessary or important for providing a positive enabling environment for community forests. We expected that a diagnostic tool based on these success factors would provide useful insights in the context of CFEs managed by CFUGs. Of the five factors Baynes et al., identified as affecting community forestry success, they found that secure property rights and material benefits for community members were necessary, but not sufficient, conditions. Reductions in socio-economic and gender-based inequality, democratic, transparent, and equitable intra-community forest group governance, and government support were important, but were neither necessary nor sufficient conditions for community forestry success.

We briefly summarize findings from Baynes et al. (2015) regarding the five success factors. Success factor 1 (land rights and secure tenure) allowed community members to access land, exclude outsiders, withdraw resources, manage land, and, in some cases, lease or sell land to others, thereby increasing communities' motivation and capacity to conserve forests. Success factor 2, transparent and equitable intra-community forest group governance, was associated with higher levels of internal management and decision-making capacity and social cohesion. Success factor 3, government support, tended to strengthen relationships within communities and between communities and external actors. Conversely, lack of government support and poor governance practices, such as patronage or corruption, reduced community capacity and motivation to engage in community forest (CF) activities. Success factor 4, reduced socio-economic and gender-based inequality, was important because greater inequality tended to be associated with a decrease in social cohesion and increased conflict, thereby reducing motivations for engaging in collective action. Success factor 5, the provision of material benefits to community members, gave community members a tangible reason to engage in collective action while potentially strengthening social cohesion.

To operationalize Baynes et al.'s (2015) model as a diagnostic tool, we developed a set of indicators for each of the five success factors and then piloted the tool by collecting data on those indicators for 12 CFEs managed by CFUGs in Nepal. Our purpose was not to validate the model but rather to illustrate how the model could be operationalized as a tool for identifying potential intervention points for policy and programmatic reforms aimed at improving the enabling environment for CFUGmanaged CFEs.

\section{Methods}

To ascertain whether and how the five success factors were manifested among CFUG-managed CFEs, we collected primary data from 12 CFEs managed either by CFUGs or a group of CFUGs. The sampling strategy captured timber, NTFP, 
and ecotourism enterprises, areas with long histories of intensive forest management interventions, and major ecological regions. Three clusters of districts were identified (Fig. 1). The Kavre-Dolkha-Sindhupalchowk-Ramechhap cluster is located in Nepal's mountain and hill area, which is characterized by intense forest-related activities and long-term support from international forestry organizations. Many timber and NTFP enterprises are present in this area.

Numerous ecotourism enterprises operate in the Chitwan cluster, which is located in the Terai region. The Nawalparasi-Dang-Banke cluster, which is also in the Terai region, supports many timber and NTFP enterprises. The 12 CFEs were purposefully selected so as to include a diversity of products produced or services provided (Table 1). The CFEs selected included two sawmills, three essential oil extraction (e.g., lemongrass, chamomile, citronella) enterprises, two ecotourism enterprisers, a producer of hand-made paper, a pine resin extraction enterprise, a producer of wood apple juice, a bio-briquette manufacturer, and an organic manure business.

Most of the CFEs operated at a very small scale and had difficulties sourcing raw materials and developing reliable markets. Timber harvesting was not a government priority and the government discouraged timber extraction by CFEs. Reliable data on the total number of CFEs in the study sites was not available.

Data were collected through focus group interviews, one group per CFE. The participants in the 12 focus groups included CFUG executive committee members, general members, and CFE managers. In selecting participants, we aimed for representativeness that included women, general forest users, Dalit, ethnic group members, and the poor. The Dalits are members of the lowest caste group in Nepal and were traditionally considered untouchables by members of higher castes. The number of participants varied from 5 to 20 participants, depending on the size of the

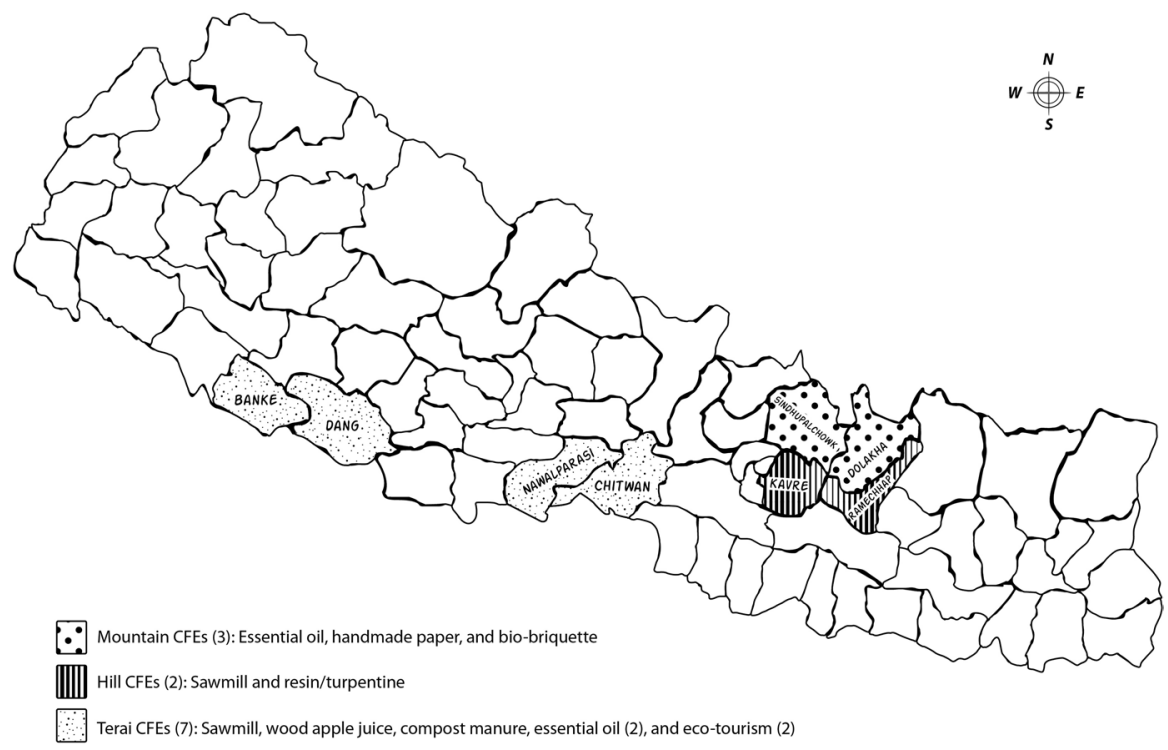

Fig. 1 Districts in Nepal where CFEs included in the study are located 


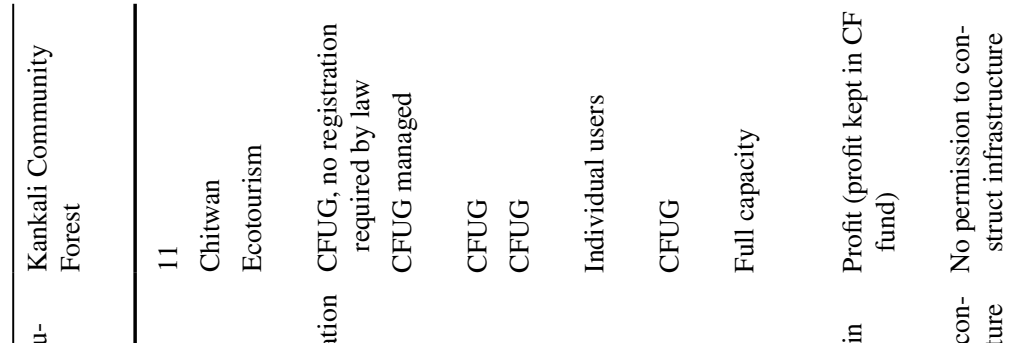

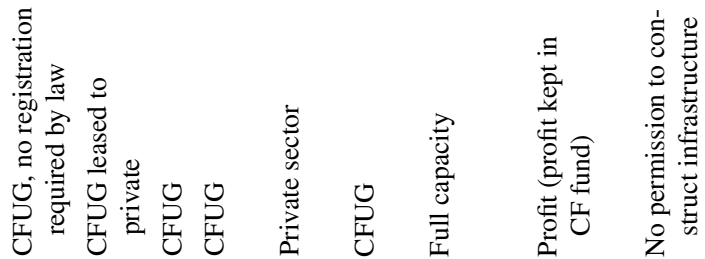

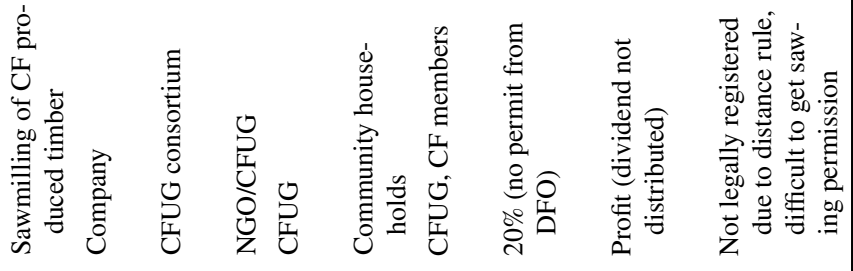

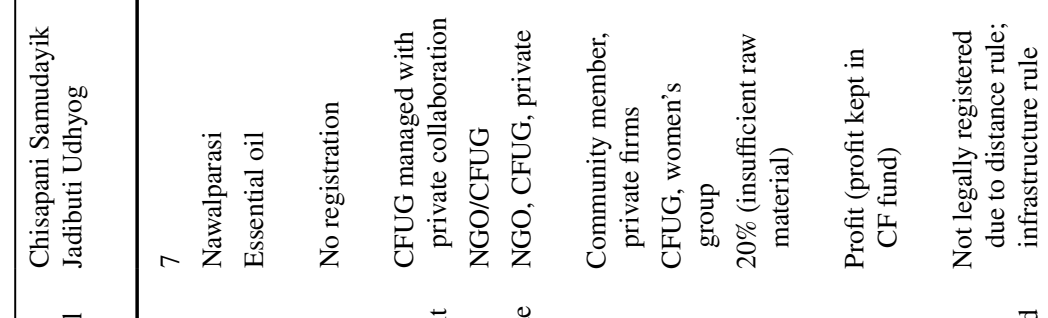

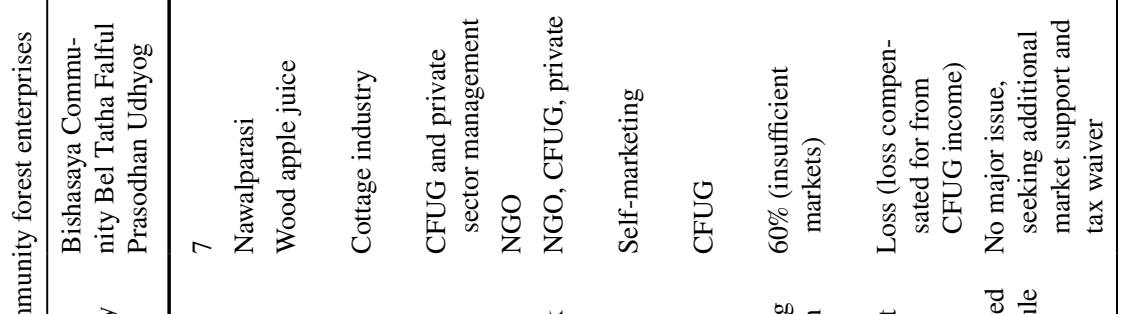

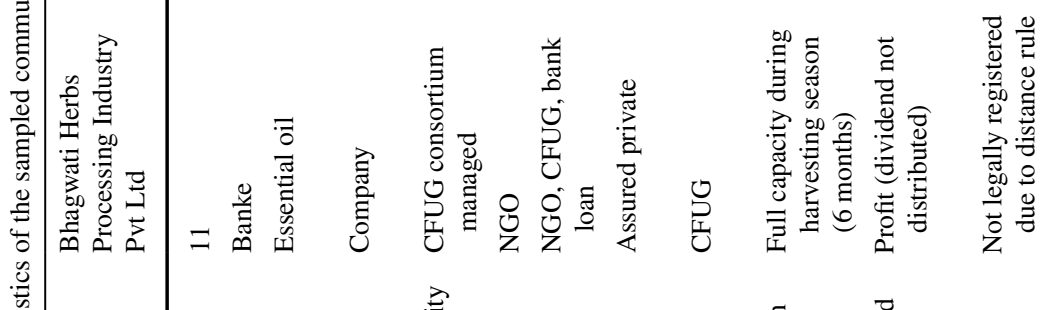

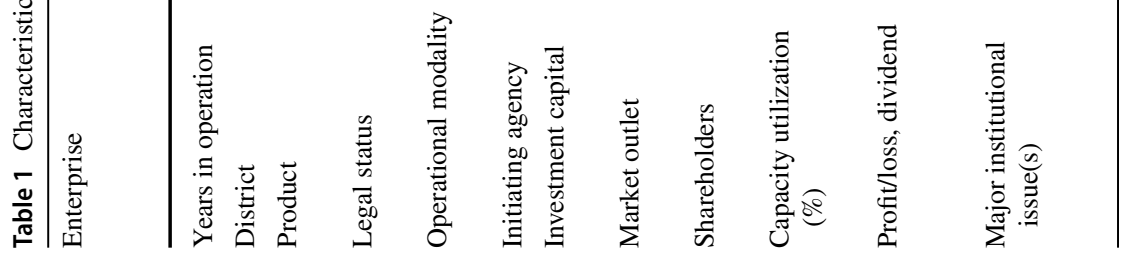




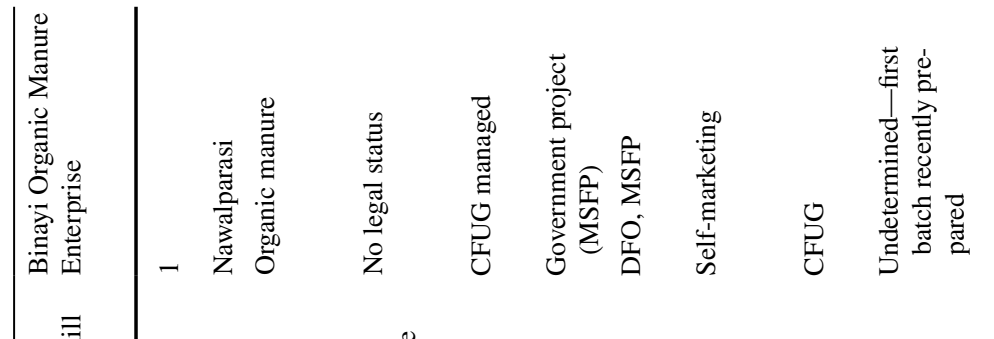

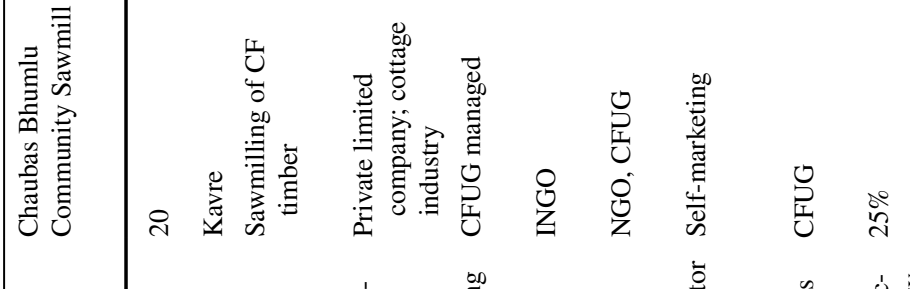

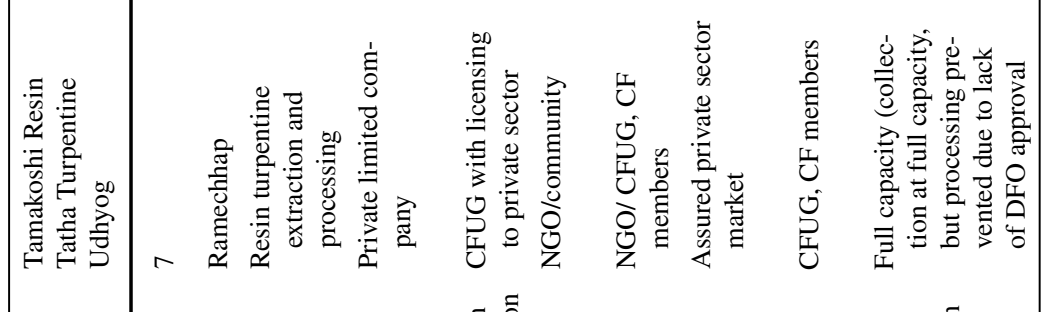

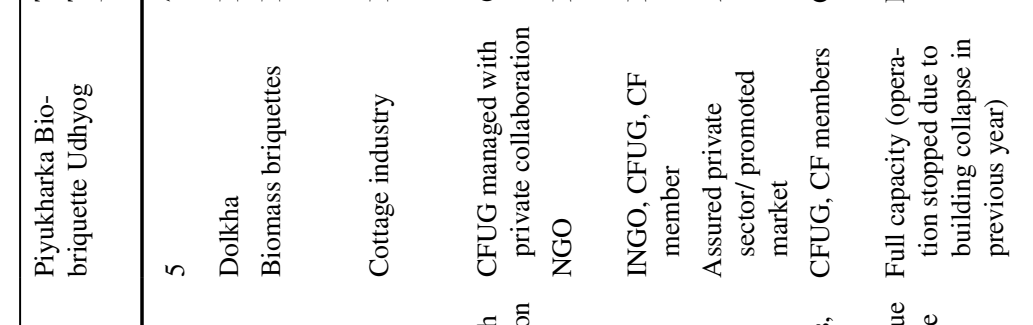

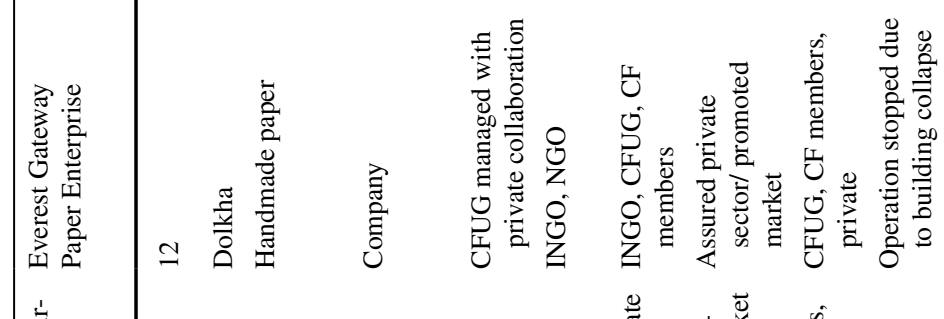

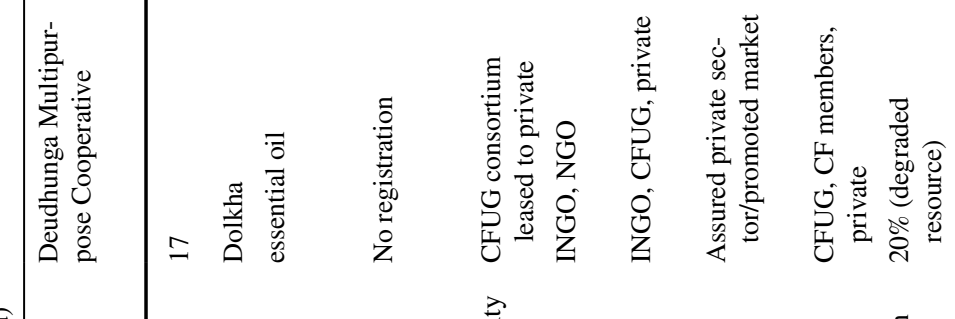

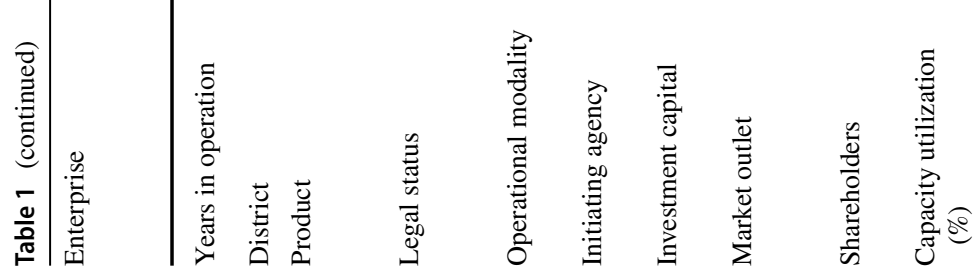




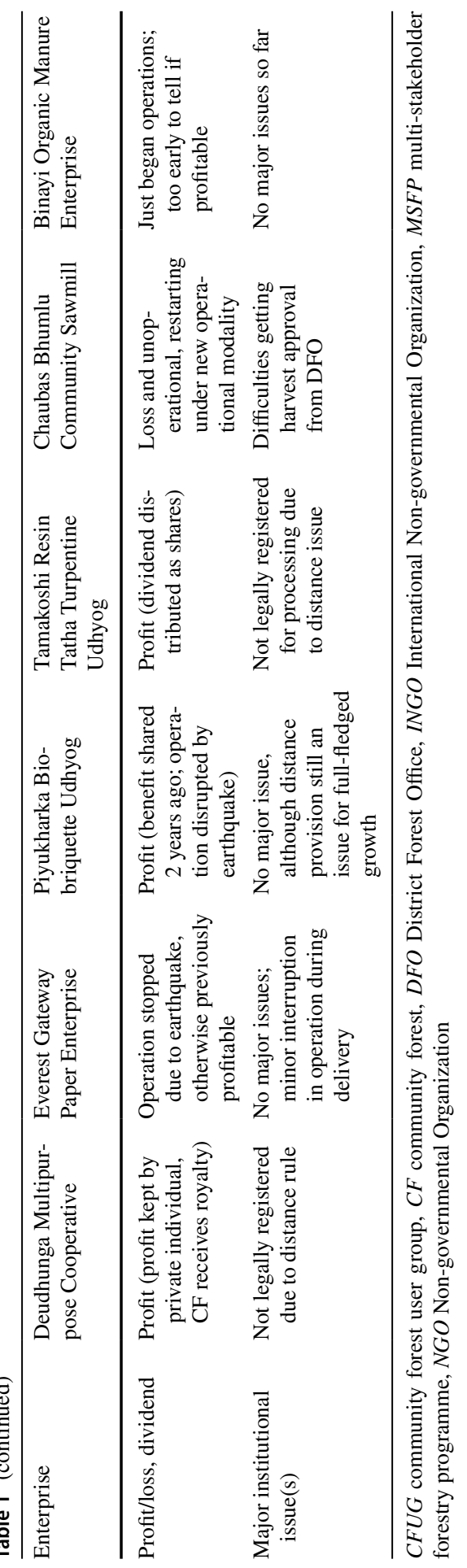


CFE and participant availability. The research team members took handwritten notes and audio-recorded interviews. To validate the interview data, notes were taken on CFUG operation plans and meeting minutes, as well as CFE-related documents. Field observations of enterprise operations supplemented the archival and interview data.

A comprehensive checklist with two components guided the focus group interviews (Supplement 1). The first component collected information about CFE establishment, legal status, operations and management behaviour, relationships between CFUGs and CFEs, contributions of CFEs to the local community, problems faced by CFEs, the role of the government forest agency, and prospects of private sector partnerships.

The second component was a set of 44 quantitative indicators for the five success factors framed by Baynes, et al. (2015) and contextualized for CFEs in Nepal based on literature on community forest institutions (such as Maraseni et al. 2014; Springate-Baginski et al. 2003) and the authors' field experience working with CFEs and CFUGs in Nepal. The indicators used for each success factor can be found in the table associated with that factor in the results section.

Twenty-nine of these indicators were based on the perceptions of focus group participants. Fifteen indicators were collected from or validated using CFUG and $\mathrm{CFE}$ records. Twenty-nine of the indicators were measured using Likert scales ranging from 1 to 5 (very poor, poor, medium, good, and very good for some indicators and very low, low, medium, high, very high for other indicators). The Likert scale responses represent the perceptions of the participants, and definitions for the points on the scale were not provided. As a result, it cannot be determined whether participants in different CFEs had the same conception for what constituted, for example, poor or good for a given indicator. For 15 variables, yes/no responses were recorded. The results for the yes/no variables were reported as the percentage of the 12 participating CFEs for which the condition was present. One variable was recorded as the percent share of investment shares and dividends distributed by the 12 CFEs. Key informant groups were asked to arrive at consensus figures for the quantitative indicators. For the analysis, we divided the responses based on mean value of indicator ratings in Likert scales into terciles categorized as low (1.00-2.33), medium (2.34-3.66) and high (3.67-5.00). Indicators were not combined within success factors since each component represents a different dimension of that factor.

We used seven indicators to assess success factor 1 , secure tree and land rights. Higher values for four of the indicators (perceptions of: tenure security following CFUG establishment, tenure security following CFE establishment, the extent to which CFUGs could make rules, and the degree to which forest tree cover quality has improved due to tenure rights devolution) were assumed to be indicative of a more positive enabling environment. Higher values for the fifth indicator, perceptions of the extent to which the District Forest Office (DFO) influences CFUG rules, were assumed to indicate a less positive enabling environment for success factor 1. The sixth and the seventh indicator, whether CFEs can be established when a community forest is absent and CFUGs themselves could set forest rules, were presence/ absence variables. Higher values for these two indicators were assumed to indicate that more of the focus groups perceived that it was possible to establish a CFE even 
if the community did not have forest rights, and that the enabling environment was thus more positive.

To assess success factor 2, intra-community forest user group governance, we used 11 indicators. Of these, three indicators were measures of governance transparency (e.g., regular meetings, audits, clear rules). Seven indicators were measures of equity: four focused on whether women, the poor, and disadvantaged groups (DAGs) were represented in decision-making positions within CFUG and CFE management and three measured perceptions of the effectiveness of the participation of women, the poor, and DAGs in CFUG meetings. The 11th indicator measured the extent to which private investment (internal and external) was welcomed. It was selected as reflective of the capacity of the CFE to negotiate with the private sector. For all of the factors, higher values were assumed to indicate a more positive enabling environment relative to success factor 2 .

Success factor 3, government support, was measured using eight indicators. Four of the indicators measured perceptions about the extent to which the government provided support for improving the management capacity of the CFUGs and CFEs or their capacity to attract private investment. Two of the indicators measured perceptions about the extent to which government support fostered forest use by the poor and broad-based participation in trainings. For these first six indicators, higher scores were assumed to indicate a more positive enabling environment relative to success factor 3. The additional two indicators measured the extent to which the key informant groups perceived that government activities undermined the success of CFEs. For these two indicators, higher scores were assumed to indicate a less positive enabling environment relative to success factor 3 .

To assess success factor 4 , socio-economic status and gender inequality, we collected information on 14 indicators. We followed Baynes et al.'s (2015) approach of using indicators of social cohesion and conflict as proxies for assessing social inequality. We identified 9 indicators contributing to social cohesion and 5 contributing to social conflict (the converse of social cohesion). Three of the social cohesion indicators measured perceptions of the extent to which community members were involved in CF activities or executive committee (EC) meetings. Two indicators measured perceptions of the capacity of the EC and community leaders to reduce caste-based discrimination. One indicator measured perceptions of the EC's ability to resolve conflicts and another measured the degree to which community institutions foster community cohesion. We also determined whether inclusive community institutions were present and whether the CFUG had sponsored capacity building programs. We included the capacity building question because Baynes et al.'s study found that capacity building tended to result in greater social cohesion. For all of the social cohesion indicators, a higher value was indicative of greater social cohesion, which in turn was indicative of a more positive enabling environment for success factor 4. Social conflict indicators included perceptions of the degree to which DAG are discriminated against in public spaces, perceptions of wage inequalities within the CFE for women, perceptions of the frequency with which caste-based conflicts occur, perceptions of the degree to which conflicts inhibit forest management or enterprise development goals, and the existence of current or past social conflict. For the social conflict indicators, a lower score was indicative of less social conflict, 
which in turn was assumed to be indicative of a more positive enabling environment for success factor 4 .

We used four indicators to measure success factor 5, the provision of material benefits to community members. Three of these were measured as dichotomous variables (presence/absence), with one indicator measuring whether local communities enjoyed material benefits from CFUGs, another measuring whether the CFEs generated employment and income for local communities, and the third measuring whether the CFUG had pro-poor benefit-sharing provisions. One indicator measured the share of CFE investment shares and dividends that was distributed among the poor and DAG. For all four indicators, a higher score was assumed to indicate a more positive enabling environment relative to success factor 5 .

\section{Results}

We discuss the five success factors in the context of the CFUGs that operate CFEs. For each success factor, we provide some background context about the communities, CFUGs, and the sampled CFEs. We describe the results from our analysis of the factor's indicators and supplement the indicator results with insights from the qualitative data set.

\section{Success Factor 1: Secure Tree and Land Rights}

Rights over forests transferred to CFUGs provided the foundation for CFE establishment. Tenure rights for CFUGs in Nepal are defined as the rights to manage CFs and harvest forest products such as firewood, timber, and NTFPs in a sustainable way in accordance with an operational plan approved by a government agency, generally the DFO (HMG/N 1995). The ability to exercise commercial extraction rights, particularly for timber, is considered vital for CFE success (Macqueen 2013). Although Nepalese CFUGs were not legally provided commercial harvest rights to timber, they exercised de facto tenure rights to provide the raw materials for CFE operations, capital for CFEs' establishment and operating expenditures, and management support. For enterprises that were not formally registered, the CFUGs' DFOapproved operational plans provided a legal framework under which CFEs could operate. CFUGs also provided a letter or brand name when the enterprises were not formally registered and would otherwise be unable to provide valid invoices or bills. Additionally, CFUGs served as a channel for CFEs to receive donor support for investment, technology, infrastructure, or market support.

The mean perception scores for success factor 1 indicators showed a medium value for perceived tenure security after CFE establishment (Table 2). Scores for this indicator varied from "very low" to "high", indicating the existence of considerable differences for this indicator across the 12 CFEs. This represented a drop from CFUG establishment following rights devolution, when the averaged value for perceived tenure security was high, and the range in values for this indicator varied from "medium" to "high". 
Table 2 Scores for secure tree and land rights indicators

Likert scale data

Range and average of indicator score

and ranking

Perceptions of tenure security after the establishment of CFUGs

3-5; 4.4 (high)

Perceptions of tenure security after the establishment of CFEs

$1-4 ; 2.5$ (medium)

Perceptions of the degree to which forest tree cover quality has improved as a result $\quad 3-5 ; 3.9$ (high) of tenure rights being devolved

Perceptions of the extent to which rules set by CFUG are observed by forest users $\quad 3-5 ; 3.9$ (high)

Perceptions of the extent of DFO influence in the formation of CFUG rules

3-5; 3.9 (high)

Presence/absence data

Percent of CFEs in which indicator

is present and ranking

CFEs can be established in the absence of a community forest

0 (low)

CFUG sets rules for forest use

100 (high)

In explaining this drop, a member of Gobardiha sawmill's management team in Dang district observed,

We had felt that we were the owners of our forest and were almost at 5 on this scale. But after being rejected after several visits to the DFO to get our enterprise registered, we now feel we have been granted nothing and that we are no more than a 2 .

None of the CFE focus groups perceived that it was possible to establish a CFE in the absence of tenure rights to a community forest. The CFE management teams expressed frustration regarding a forest regulation known as the distance provision, which requires that CFEs be located a minimum of $0.25 \mathrm{~km}$ or $1.0 \mathrm{~km}$ distant from the forest boundary (the distance required is dependent on the ecological region in which the CFUG is located). For products harvested according to a DFO-approved operational plan and for local community consumption, no legal or administrative barriers were reported.

All of the CFE focus groups perceived that their CFUGs had the right to establish forest use rules. DFO influence over those rules was perceived to be high, and none of the CFEs provided a score of low or very low for this indicator. Quantitative data that would allow a determination as to whether informants perceived DFO influence in rule-making as positive, negative, or neutral was not collected. However, as indicated in the description of success factor 3 results, DFO influence was viewed as negative rather than helpful. Levels of members' compliance with the rules set by CFUG managers were perceived as high, and respondents perceived that exercising their tenure rights enabled the CFUGs to maintain a high level of forest quality, thereby increasing the likelihood that CFUG members would have long-term access to forest products. The respondents indicated that before rights devolution, government enforcement presence was weak, and the forests were degraded. Once communities acquired forest rights, CFUGs developed conservation and harvesting 
rules with community input and implemented community-based enforcement systems. The combination of rules that are perceived as legitimate, together with locallevel enforcement, has improved forest conditions over time. The high score for perceptions of member compliance together with the high score for perceptions of CFUG ability to maintain forest quality suggest that the CFUGs have the capacity to enforce forest use rules.

\section{Success Factor 2: Intra-community Forest Group/CFE Governance}

The 12 CFEs were established with support from various actors, including international non-governmental organizations (INGOs), government projects, District Forest Offices (DFOs), CFUG executive boards, CFUG member entrepreneurs, community members, and private forest sector companies. In eight cases, a forestry sector non-governmental organization (NGO) or INGO offered starting capital, which in some cases was converted into shares for poor households. Other shareholders included the CFUG, individual CFUG members as private investors, and some forest product companies. The Federation of Community Forest Users Nepal (FECOFUN), Nepal's national umbrella organization of CFUGs, played an instrumental role in establishing and promoting CFEs.

According to the Private Firm Registration Act, the Company Act, and the regulations associated with these acts, all forest-based production and value addition enterprises targeting markets beyond the local level must register with the Department of Industry, either as a small or cottage industry (SCI), medium, or large industry (MOI 2010). A SCI registers with the Department of Small and Cottage Industries (DCSI). These enterprises can be sole proprietorships or partnerships. Enterprises with many owners must register under the 2006 Companies Act at the Company Registrar's Office. Unregistered companies can neither legally undertake production nor issue any formal product marketing documents. However, the law has no provision for registering an enterprise owned by CFUGs.

Two CFEs were registered as SCIs, with the CFUG chairperson as the proprietor. This meant that the CFE was registered as a private business, even though in practice it was CFUG-owned. Five of the CFEs were registered under the Company Act. The two ecotourism enterprises felt no need to register as they provided services only within their territory. Three CFEs were not registered at all. The only legal documentation that CFEs lacking registration had was the mention of their production activity in their CFUG's DFO-approved operation plan. These CFEs used their CFUG's letterhead to issue information about the forest products they processed and sold. Although these are not legally valid documents, none of the CFEs had encountered problems with using them.

The CFEs were managed either by a single CFUG, through a consortium of CFUGs, or in collaboration with private sector partners. To run the CFE, the CFUG generally created a management body and appointed a manager. A review of the operating structures showed that the CFEs were completely under community control, even when legally they appeared to be private businesses. The CFUGs determined the management committee composition, and were responsible for ensuring 
adequate representation by gender, poverty status, and ethnicity. The CFUGs or a consortium of CFUGs determined how investment shares would be allocated, inclusion of the poor in the share allocation, profit sharing provisions, and monitoring structure. For CFEs operated by multiple CFUGs, the management boards included at least one representative from each CFUG that was a CFE member. The CFE management was responsible for making rules for collecting CFUG input, managing production activities, market coordination, conducting the annual general assembly meeting, and regular financial audits.

The results for transparent and equitable intra-community governance were mixed (Table 3). All the CFUGs had regular general and EC meetings, public audits of financial transactions, and clear resource governance rules. Additionally, women, poor community members, and DAG were represented in all CFUG executive committees. However, the effectiveness of these groups in decision-making was perceived as medium overall. Scores for this indicator ranged from 1 to 5, indicating considerable differences across CFEs. Only half of the CFE management teams included poor community members. Broad representation increases the size of the ECs, which some CFE managers viewed as problematic. A manager of Tamakoshi Resin and Turpentine enterprise described how having to incorporate multiple groups in the CFE has affected its operations:

It is ideal to have representation and engagement of all the socio-economic groups in the CFEs, but when it comes to implementation, it is only a few

Table 3 Scores for intra-community forest user group/CFE governance indicators

\begin{tabular}{lc}
\hline Likert scale data & $\begin{array}{c}\text { Range and average } \\
\text { of indicator score } \\
\text { and ranking }\end{array}$ \\
\hline $\begin{array}{l}\text { Perceived effectiveness of participation of women in CFUG meetings } \\
\text { Perceived effectiveness of participation of DAG in CFUG meetings }\end{array}$ & $2-5 ; 3.5$ (medium) \\
Perceived effectiveness of participation of the poor in CFUG meetings & $1-5 ; 3.3$ (medium) \\
Presence/absence data & $1-4 ; 2.6$ (medium) \\
& $\begin{array}{c}\text { Percent of CFEs for } \\
\text { which the condi- } \\
\text { tion exists and } \\
\text { ranking }\end{array}$ \\
$\begin{array}{l}\text { Annual general meetings and audits conducted regularly in last 3 years (based on } \\
\text { records) }\end{array}$ & 100 (high) \\
Rules regulating resource extraction, monitoring, and land/tree maintenance are & 100 (high) \\
clear (based on interviews) & 100 (high) \\
EC meetings are held regularly (based on records) & 100 (High) \\
Women, the poor, and DAGs are on the CFUG executive committee (based on & \\
records) & 83.3 (high) \\
Females are on CFE management team (based on records) & 75.0 (high) \\
DAG are on CFE management team (based on records) & 41.7 (medium) \\
Poor community members are on CFE management team (based on records) & 58.3 (medium) \\
Welcomes private sector investment (based on interviews) & \\
\hline
\end{tabular}


in the lead. This makes collective decision making rather complicated and unsuitable for running a market-oriented enterprise.

Private investment also potentially impacts CFUG governance. External private sector partners were involved in seven CFEs. In Chisapani, a private company invested NRs 500,000 (USD 7000) to construct a processing plant on CFUG property. The CFUG has leased its land to the company for essential oil plants cultivation. The company paid daily wages to women from the community to work on these allotted lands. In the case of the Chaubas sawmill, negotiations were moving forward for management and marketing by a private firm with a $51 \%$ share investment and dividend, with the community receiving a $49 \%$ share.

The focus groups supported the idea of community members being involved in a private capacity but seven of the focus groups indicated that external private sector investment was not welcome. They claimed that external involvement would allow outsiders to reap the benefits of decades of community forest management without adequate reward for the community. In the case of the Bhagwati essential oil processing enterprise, the community refused an offer by an external private company to invest in the operation on the assumption that if an external private sector company were to take over, it would process the products at a less favourable rate than the CFE currently charges, with a negative impact on the community's welfare. Gobardiha sawmill managers made similar arguments:

We know that if we hand this over to a private company, it can overcome all these regulatory barriers and start operating without hurdles by any means... But the community will start suffering due to higher prices of services and the forest quality will be compromised.

However, if the private company originates from within the community, collaboration with the private sector may emerge as an option. For instance, in the case of the Bishasaya wood apple juice enterprise, the community had recently assigned a CFUG member to run the enterprise with a 50\% profit-sharing arrangement.

\section{Success Factor 3: Government Support}

Community perceptions of the degree to which the government supports CFEs and the CFUGs that managed them were mixed (Table 4). On average, the focus groups perceived that government support enabling CFEs to meet administrative and planning requirements was moderate, as was support for record-keeping and other management skills training. Government support for training opportunities for women, poor, and DAGs, and ensuring that the poor had access to forest products was perceived as high. Participants perceived that government support for enterprise capacity building and linking the CFE to private investment opportunities was low and that government corruption and DFO interference with CFE operations was high.

The qualitative data indicated that tension between the CFEs and the government was linked to regulations inconsistent with tenure rights devolution. The 1993 Forest Act and the 1995 Forest Regulations govern present-day forest activities, but several amendments have undermined the ability of CFEs to function profitably. Regulations 
Table 4 Scores for government support indicators

Likert scale data

Range and average of indicator score

and ranking

Perceptions of the extent of government facilitation in helping CFUGs meet admin- 2-5; 3.1 (medium) istrative and planning procedures and requirements

Extent to which government provides training for recordkeeping, infrastructure, $\quad 2-5 ; 2.4$ (medium) funding, and other management skills (based on training records)

Participation of women, the poor, and DAGs in trainings (based on training records) 3-5; 3.8 (high)

Perceptions of the extent to which government supports enterprise capacity build- $1-5 ; 2.3$ (low) ing

Perceptions of the extent to which DFO supports bringing private sector investment $1-4 ; 1.8$ (low) to CFEs

Perceptions of the degree to which patronage, corruption, and interference occurs 4-5; 4.6 (high) on the part of DFOs and other government agencies

Perceptions of the degree to which the CFE's ability to operate is inhibited by DFO $1-5 ; 3.8$ (High) activities

Presence/absence data

Percent of CFEs in which indicator is present and ranking

Perceptions that government provision exists for forest use by the poor (validated $\quad 91.6 \%$ (high) through records)

designate the DFO as the implementing agency at the local level with the authority to approve all forest-related activities. This gives DFO officials enormous influence over the CFEs. Activities such as tree marking, issuing cutting orders, and sawing orders all have to be approved by the DFO. However, the DFO lacks the resources to carry out its responsibilities (Acharya et al. 2009).

The distance provision, which states that no permanent forest products processing structure can be built within community forests (HMG/N 1995), was a major source of tension. Since most forests near human settlements have been converted into community forests, it is almost impossible to find locations for operating CFEs consistent with the distance standards. As a result, five CFEs were established on community forest in violation of the distance provision. This, in turn, means they cannot be registered. The resentment that CFE managers have toward the DFOs with respect to the minimum distance provision is exacerbated because DFOs have been known to grant licenses to private timber enterprises by manipulating the distance criteria.

\section{Success Factor 4: Socio-Economic Status and Gender-Based Equality}

Nepal's CF guidelines aim to ensure inclusiveness in CFUG management and benefit-sharing in favour of the very poor and disadvantaged groups, accounting for social status differences between Dalits, indigenous groups, and high caste groups 
(Brahmin/Chhetri). The guidelines require communities to develop wealth rankings of households, and ensure female, indigenous, and Dalit representation so as to reduce the scope for elite capture, primarily by high caste males. Half of the Executive Committee (EC) members must be women, with representation from the poor, Dalit and indigenous groups. Male EC members must also include poor, Dalit, and indigenous group members in proportions reflecting the community's composition (MFSC 2009).

The focus groups perceived the enabling environment with respect to socio-economic status and gender inequality to be positive, as reflected in medium to high indicator scores for social cohesion (Table 5) and low scores for conflict (Table 6).

Social cohesion indicators pertaining to equality of participation opportunities were medium (participation of the poor) to high (all households and DAG CFUG members). On average the focus groups perceived that their EC had a high capacity to reduce caste-based discrimination and resolve conflicts.

The DFOs emphasize that the EC should ensure participation of disadvantaged groups such as women, the poor, and Dalits in CFUG activities. This contributes to a reduction in caste-based discrimination in CFUG activities. Such provisions are rarely emphasized in other social life spheres. As a result, communities perceived that the EC had a comparatively higher capacity to reduce caste-based discrimination than community leaders.

Table 5 Scores for social cohesion indicators

Likert scale data

Range and average of indicator score

and ranking

Indicators of social cohesion $^{\mathrm{a}}$

Perceptions of the ability of the EC to ensure participation of all households in CF $4-5 ; 4.4$ (high) activities

Perceptions of the regularity with which DAG CFUG members participate in EC meetings (validated through consulting records)

Perceptions of the regularity with which poor CFUG members participate in EC $1-5 ; 3.5$ (medium) meetings (validated through consulting records)

Perceptions of the capacity of the EC to reduce caste-based discrimination ${ }^{\mathrm{a}}$

Perceptions of the capacity of community leaders to reduce caste-based discrimination $^{\mathrm{a}}$

Perceptions of the ability of the EC to resolve conflicts

$2-5 ; 3.8$ (high)

$3-5 ; 4.3$ (high)

3-5; 3.7 (high)

Perceptions of the degree to which community institutions foster community cohesion

Presence/absence data

2-5; 3.7 (high)

3-5; 3.6 (medium)

Percent of CFEs in which indicator was present and ranking

100 (high)

66.7 (high)

Presence of other inclusive community institutions (i.e., mothers' or savings groups) in the community

CFUG-sponsored capacity building programs have taken place in the last 3 years

${ }^{\mathrm{a}}$ High values indicate greater social cohesion and a more positive enabling environment. Low values indicate less social cohesion and a less positive enabling environment 
Table 6 Scores for social conflict indicators

Likert scale data

Range and average

of indicator score

and ranking

\begin{tabular}{|c|c|}
\hline Social conflict indicators ${ }^{\mathrm{a}}$ & \\
\hline Perceptions of the degree to which DAG are discriminated against in public spaces & $1-3 ; 1.8$ (low) \\
\hline $\begin{array}{l}\text { Perceptions of the level of inequality within the CFE of wages and other benefits } \\
\text { for women }\end{array}$ & $1-3 ; 1.8$ (low) \\
\hline Perceptions of the frequency with which caste-based conflicts occur ${ }^{\mathrm{a}}$ & $2-5 ; 1.6$ (low) \\
\hline $\begin{array}{l}\text { Perceptions of the degree to which conflicts inhibit forest management or enter- } \\
\text { prise development goals }\end{array}$ & $1-2 ; 1.1$ (low) \\
\hline Presence/absence data & $\begin{array}{l}\text { Percent of CFEs for } \\
\text { which indicator } \\
\text { was present and } \\
\text { ranking }\end{array}$ \\
\hline Existence of current or past history of social conflict & 0 (low) \\
\hline
\end{tabular}

${ }^{\mathrm{a}}$ Low values indicative of less conflict and more positive enabling environment; high values indicative of greater conflict and a less positive enabling environment

The average score for the degree to which community institutions foster community cohesion was moderate, suggesting that social cohesion outside the CFUG/CFE environment may be less strong. Institutions such as mothers' or savings groups, whose memberships cut across social boundaries, were present in all communities, and most CFUGs had supported capacity building programs during the previous 3 years. Conversely, social conflict indicators were perceived to be low (Table 6). The capacity of the $\mathrm{CF}, \mathrm{EC}$ and local leaders to resolve conflicts was perceived as high.

\section{Success Factor 5: Material Benefits to Community Members}

All of the CFUGs structured their operations to provide for the daily needs of local communities, including pro-poor provisions, and all of the CFEs generated employment and income for local communities (Table 7). Only a small share (3.8\%) of investment shares and dividends was distributed to the poor and DAG. However, women, DAG members, and the poor enjoyed a substantial share of the employment opportunities $(42.3,43.5$, and 59.8\% respectively when averaged across the 12 CFEs.

The qualitative data revealed that the CFEs generated local employment, creating opportunities for members to earn cash income from previously unused forest resources. Managers of the Chisapani CFUG, which operated an essential oil enterprise that employed 65 women, indicated that they needed to make enough to cover operating costs, but beyond that, profit was not their motive, "We didn't establish this enterprise to make profit. Our main goal was to create employment for very poor women." The wood apple juice enterprise in Nawalparasi subsidized poorer community members' earnings. "We don't mind bearing some losses from the 
Table 7 Scores for indicators of material benefits being provided to community members

\begin{tabular}{lc}
\hline Presence/absence data & $\begin{array}{l}\text { Percent of CFEs } \\
\text { in which indicator } \\
\text { is present and } \\
\text { ranking }\end{array}$ \\
\hline $\begin{array}{l}\text { Provisions exist for material benefits of daily needs from CFUGs to local communi- } \\
\text { ties (based on records) }\end{array}$ & $100 \%$ (high) \\
$\begin{array}{l}\text { CFUG has pro-poor provisions sharing of benefits (based on records) } \\
\text { CFEs generate employment and income benefits for local communities (based on } \\
\text { records) }\end{array}$ & $\begin{array}{c}100 \% \text { (high) } \\
100 \% \text { (high) }\end{array}$ \\
$\begin{array}{l}\text { Share of CFE benefits } \\
\text { Average \% share } \\
\text { of across the } \\
12 \text { CFEs and } \\
\text { ranking }\end{array}$ \\
$\begin{array}{l}3.8 \% \text { (low) } \\
\text { Distribution of CFEs' investment shares and dividends among the poor and DAG }\end{array}$ \\
\hline (based on records)
\end{tabular}

enterprise because it is providing employment benefit to the poor members in the community," said a focus group participant, "We can compensate the losses from other sources." The Chisapani CFUG allocated some CFUG-owned land to a private institution that plants essential oil species. Women from households participating in the CFUG could either work their own plots or work for wages in the private firm's plots.

CFEs also contributed to CFUG funds. The resin enterprise paid the CFUGs a royalty of NRs 900 (USD 12) per quintal (100 kg) for 160 quintal of resin collected in 2016. The Chisapani CFUG charged community members, the private company cultivating essential oil plants in the $\mathrm{CF}$ plot, and external customers for extracting essential oil. The Baghmara CFUG received licence fees for elephants carrying tourists into its territory. The Kankali CFUG charged an entrance fee to its picnic spot and swimming pool. In other CFEs, the CFUG received funds as dividends from the CFEs or residual incomes after deducting expenses from the receipts of their marketed products. The wood apple enterprise in Nawalparasi, bio-briquette enterprise in Sindhupalchowk, ecotourism enterprises in Chitwan, and essential oil enterprise in Banke received dividends or residual profits from their enterprises. These funds were spent for activities in accordance with the government's community forestry guidelines: forest conservation and development, livelihood opportunities for the poor, skills training, and social development activities related to health, education, or drinking water.

CFEs also provided important services to the community. The Gobardiha sawmill provided low-cost access to a sawmill while minimizing the timber consumption rate. Households requiring small amounts of wood for making beds or doors are granted rights to the trunks of trees harvested by the CFUG. The tree trunks generally provide more wood than the poor households require. Low income households may lack the capacity to use all the timber, thereby leading to non-consumption or a waste of a scarce product. However, since the CFUG sawmill provided households with the exact amount of timber needed, any extra timber could be given to another 
household. This reduced logging requirements and transportation costs while offering CFUG members an alternative to the high fees charged by private sawmills. It also provided timber to poor households that needed small quantities of wood. CFEs that were registered as companies had three types of shares: shares that were held by donors, such as the US Agency for International Development, but which were allocated to poor households, shares belonging to the CFUG itself, and privately held shares belonging to CFUG member households. Some households were shareholders with a dividend-sharing arrangement.

\section{Discussion}

We developed a diagnostic tool that combined Baynes et al.'s (2015) five CF success factors with a set of indicators customized for Nepal and used the tool to assess 12 CFUG-managed CFEs in Nepal. The assessment revealed that the focus groups perceived that they had strong rights to regulate forest use, as well as the capacity to enforce those rights. However, they perceived their forest rights following CFE establishment to be moderate, a downward shift from how they had perceived their rights before CFE establishment. This difference indicates that a gap exists between the CFUGs' presumed forest rights and their rights in practice. The qualitative data showed that this gap has emerged due to inappropriate regulations, such as the distance provision, and inconsistent and inappropriate application of regulations that constrain the ability of CFUGs to operate commercially viable CFEs. Other studies have found that Nepal's forest bureaucracy constrains the ability of communities to use and market forest products (Dongol et al. 2002; Sunam et al. 2013). It is worth recalling that success in forest resources commercialization in Mexico and elsewhere has its roots in favourable tenure rights, accompanied by a regulatory framework that encourages sustainable practices (Antinori and Bray 2005; Bray et al. 2006; MacQueen 2013). Key interventions for Nepal suggested by the diagnostic are regulatory reforms, notably revising the distance provision, so that CFEs can have production and processing facilities in their CF. A provision that allows CFUGs to appeal DFO-level decisions regarding registration might decrease tensions between the DFO and CFUGs.

The diagnostic showed that the CFUGs display many good governance attributes, such as clear rules, public audits, and inclusive management structures. However, it is less clear whether marginalized groups participate effectively in decision-making. Inappropriate regulations undermined the enabling environment with respect to success factor 2. The CFEs' precarious legal footing limits their engagement in valueadded activities and in generating employment and income. This limits the ability of government agencies to support CFEs. The minimum distance policy was cited as the primary reason for lack of private sector interest in partnering with the CFUGs. Creating the legal conditions needed for CFEs to thrive requires revisiting two questions: (1) whether the fear about resource sustainability implicit in the distance and boundary criteria provision is warranted, and (2) how to improve the prospects for legalizing CFUG-managed CFEs so they can attract private sector investments and expand their capacity to market forest products and ecotourism services. 
The diagnostic revealed that success factor 3, government support, was the weakest of the factors. Support for enterprise and market development was perceived as very weak. Moreover, many participants felt the government hindered profitable CFE operations owing to corrupt practices and interference by the DFO. Interventions indicated by the diagnostic include an expanded focus on providing government support for CFE capacity building, market development assistance, and joint public-private investment. Equally important are policy reforms that support transparency and accountability, as well as streamlining of regulations.

With respect to success factor 4, government policies and directives for CFUG formation and operation have helped foster inclusiveness by gender, ethnicity, and economic status. All the communities had adopted the minimum criteria for incorporating women, the poor, and DAGs into CFUG and CFE management structures. Additionally, all CFEs have mechanisms to ensure employment and income opportunities for the poor and marginalized groups. However, ensuring effective participation of socio-economically disadvantaged community members in decision-making is a hurdle that most CFUGs and CFEs have not yet overcome. Caste and ethnicitybased discrimination remains a barrier to collaboration in social life including economic enterprises in Nepal (Pandey et al. 2006; Gurung et al. 2013; Rutt 2015).

The diagnostic revealed that CFUG-managed CFEs delivered material benefits to community members, particularly in the form of subsistence needs. However, employment and income generating opportunities remain limited. Scaling up these opportunities requires policy reforms that provide CFEs with legal status together with support that encourages more private or joint public-private investment in CFEs.

\section{Refining the Model for Assessing CFE Enabling Environments}

Our study highlights refinements that are needed to apply the Baynes et al. (2015) model to the evaluation of tenure and forest governance enabling environments for CFUG-managed CFEs. The model needs to add a governance component that assesses the roles and composition of external investors, their influence on CFE governance, and their economic and political power relative to local actors. A component that measures private sector investment characteristics and how those influence benefit sharing arrangements, as well as ecological and social outcomes, is also needed.

\section{Limitations of the Study and Diagnostic Tool}

We collected data from CFUG/CFE leaders and actively engaged members because persons not active in the CFUGs and CFEs were generally unwilling to participate in the study. As a result, our indicators for operationalizing the Baynes et al. (2015) framework worked well for assessing success factors 1,2 , and 3 , the factors most closely linked to tenure rights and governance, and which CFUG/CFE leaders and active members were familiar with. However, the diagnostic tool was less effective for evaluating success factor 4 , which deals with the broader social context, and 
success factor 5, which examines the broader impacts of CFE operations. Input from a broader set of community members could yield more useful results for these two factors but might require providing incentives to attract more diverse participation. A limitation of the indicators is that they were developed for assessing the tenure and forest governance-enabling environment for CFEs in Nepal. Although most of the indicators are appropriate for a variety of contexts, some, such as those referring to caste-based discrimination, may require adjustment when used elsewhere.

\section{Next Steps}

We suggest several avenues for future research. Testing the diagnostic tool in other contexts, to develop a standard checklist where users can apply relevant indicators and discard others that are less relevant, is a logical next step. Another next step is to incorporate a more in-depth assessment of the social, economic, and business outcomes associated with CFUG-managed CFEs. A diagnostic tool that includes an outcomes element can enhance understandings of the relationship between the success factors and on-the-ground impacts. For example, incorporating an ecological outcomes element into the diagnostic tool will enable researchers and practitioners to identify which variables, such as scale of business operations or certification, are important for sustainability.

\section{Conclusion}

Investments in CFEs have been initiated through national and international forestry projects, CF communities, government projects, and the private sector. However, regulatory obstacles have inhibited the willingness of communities to make capital investments in expanding CFEs. Regulatory reform together with support for modern inputs, market development, and marketing has potential for improving CFE effectiveness. Regulatory reform would allow communities and policy makers to realistically evaluate the potential of CFEs to contribute to livelihoods. A closely monitored trial would improve understanding of the potential of CFUG-managed CFEs to contribute to the economic betterment of local communities.

Acknowledgements Funding support was provided by the CGIAR Research Program on Policies, Institutions, and Markets (PIM), led by the International Food Policy Research Institute (IFPRI), and by the Center for International Forestry Research (CIFOR).

Open Access This article is licensed under a Creative Commons Attribution 4.0 International License, which permits use, sharing, adaptation, distribution and reproduction in any medium or format, as long as you give appropriate credit to the original author(s) and the source, provide a link to the Creative Commons licence, and indicate if changes were made. The images or other third party material in this article are included in the article's Creative Commons licence, unless indicated otherwise in a credit line to the material. If material is not included in the article's Creative Commons licence and your intended use is not permitted by statutory regulation or exceeds the permitted use, you will need to obtain permission directly from the copyright holder. To view a copy of this licence, visit http://creativecommons.org/licen ses/by/4.0/. 


\section{References}

Acharya KP (2002) Twenty-four years of community forestry in Nepal. Int For Rev 4(2):149-156

Acharya D, Vaidya MR, Subedi R, Lamshal P, Gurung B (2009) Organisational and human resource aspects of forestry sector. Report of the task force for democratising forest sector in Nepal. Nepal Foresters Association, Kathmandu, Nepal

Albano A, Pandit BH, Kumar C, Belcher B (2008) Developing community-based forest enterprises in Nepal. CIFOR Livelihood Brief No.10. Bogor, Indonesia, Center for International Forestry Research (CIFOR). 4. https://hdl.handle.net/10568/19961. Accessed 25 Jan 2020

Antinori C, Bray DB (2005) Community forest enterprises as entrepreneurial firms: economic and institutional perspectives from Mexico. World Dev 33(9):1529-1543

Banjade MR, Paudel NS, Mwangi E (2017) Political economy of forest tenure reform implementation in Nepal: evolution, contestation, outcomes and challenges. J For Livelihood 15(2):1-14

Baynes J, Herbohn J, Smith C, Fisher R, Bray D (2015) Key factors which influence the success of community forestry in developing countries. Glob Environ Change 35:226-238. https://doi. org/10.1016/j.gloenvcha.2015.09.011

Baynes J, Herbohn J, Dressler W (2016) Power relationships: their effect on the governance of community forestry in the Philippines. Land Use Policy 54:169-176

Bray DB, Antinori C, Torres-Rojo JM (2006) The Mexican model of community forest management: the role of agrarian policy, forest policy and entrepreneurial organization. For Policy Econ 8(4):470-484

Central Bureau of Statistics (CBS), Government of Nepal (2011) Nepal living standards survey 2011. Central Bureau of Statistics, Government of Nepal, Kathmandu

Chand N, Kerr GN, Bigsby H (2015) Production efficiency of community forest management in Nepal. For Policy Econ 50:172-179

Cubbage FW, Davis RR, Rodríguez Paredes D, Mollenhauer R, Kraus Elsin Y, Frey GE, González Hernández IA, Albarrán Hurtado H, Salazar Cruz AM, Chemor Salas DN (2015) Community forest enterprises in Mexico: sustainability and competitiveness. J Sust For 34:623-650

Department of Forest Research and Survey (DFRS) (2015) State of Nepal's forests. Forest resource assessment (FRA) Nepal. Department of Forest Research and Survey, Kathmandu

Dhungana SP, Bhattarai RC (2008) Exploring economic and market dimensions of forestry sector in Nepal. J For Livelihood 7(1):58-69

Dongol CM, Hughey KF, Bigsby HR (2002) Capital formation and sustainable community forestry in Nepal. Mt Res Dev 22(1):70-77

Gurung A, Bista R, Karki R, Shrestha S, Uprety D, Oh S (2013) Community-based forest management and its role in improving forest conditions in Nepal. Small Scale For 12(3):377-388. https://doi. org/10.1007/s11842-012-9217-z

His Majesty's Government of Nepal (HMG/N) (1995) Forest Regulation 1995. His Majesty's Government of Nepal. Nepal Gazette. 1995/04/03

Koirala G, Acharya RP, Dhakal S, Karki G (2013) A rapid assessment of forest based enterprises in Nepal. Multi Stakeholder Forestry Programme, Kathmandu

Kunwar SC, Ansari AS, Luintel H (2009) Non-timber forest products enterprise development. J For Livelihood 8(2):39-50

Lamsal P, Pant KP, Bhatta DR (2017) Forest-based micro and small enterprises in Nepal: a review of status, constraints, scope and approach. Int For Rev 19(1):42-54

Larson AM, Dahal G (2012) Forest tenure reform: new resource rights for forest-based communities. Conserv Soc 10(2):77-90

Macqueen DJ (2008) Forest connect: reducing poverty and deforestation through support to community forest enterprises. Int For Rev 10(4):670-675

Macqueen D (2013) Enabling conditions for successful community forest enterprises. Small Scale For 12(1):145-163. https://doi.org/10.1007/s11842-011-9193-8

Maraseni TN, Neupane PR, Lopez-Casero F, Cadman T (2014) An assessment of the impacts of the REDD+ pilot project on community forests user groups (CFUGs) and their community forests in

Nepal. J Environ Manag 13:37-46

MFSC (2009) Community forestry programme guidelines. Government of Nepal, Kathmandu

MFSC (2013) Persistence and change: review of 30 years of community forestry in Nepal. Government of Nepal, Kathmandu

Ministry of Finance (2016) Economic survey fiscal year 2016/17. Government of Nepal, Kathmandu 
Ministry of Industries (2010) Industrial policy 2010. Government of Nepal, Kathmandu

Pandey TR, Mishra S, Chemjong D, Pokhrel S, Rawal N (2006) Forms and patterns of social discrimination in Nepal: a report. UNESCO Kathmandu. Series of monographs and working paper no: 8 .

Pandit R, Bevilacqua E (2011) Forest users and environmental impacts of community forestry in the hills of Nepal. For Policy Econ 13(5):345-352

Persson J, Prowse M (2017) Collective action on forest governance: an institutional analysis of the Cambodian community forest system. For Policy Econ 83:70-79

Ribot JC, Lund JF, Treue T (2010) Democratic decentralization in sub-Saharan Africa: its contribution to forest management, livelihoods, and enfranchisement. Environ Conserv 37(1):35-44

Rutt RL (2015) Reconceptualizing the social contributions of community forestry as citizenship. Int For Rev 17(3):326-339

Sanchez-Bandini O, Hajjar R, Kozak R (2018) Critical success factors for small and medium forest enterprises: a review. For Policy Econ 94:35-45

Sharma BP, Lawry S, Paudel NS, Adhikari A, Banjade MR (2017) Has devolution of forest rights in Nepal enabled investment in locally controlled forest enterprises? Paper presented at the World Bank 2017 land and poverty conference: responsible land governance-towards an evidence-based approach, March 20-24, 2017, Washington, DC. Accessible at: https://www.cifor.org/wp-content/ uploads/sites/worldbank2017/Sharma_364.pdf. Accessed 25 Jan 2020

Springate-Baginski O, Yadav N, Dev OP, Soussan J (2003) Institutional development of forest user groups in Nepal: processes and indicators. J For Livelihood 3(1):21-36

Subedi B, Ghimire PL, Koontz A, Khanal SC, Katwal P, Sthapit KR, Khadka Mishra S (2014) Private sector involvement and investment in Nepal's forestry: status, prospects and ways forward. Multi Stakeholder Forestry Programme, Kathmandu

Sunam RK, Paudel NS, Paudel G (2013) Community forestry and the threat of recentralization in Nepal: contesting the bureaucratic hegemony in policy process. Soc Nat Res 26(12):1407-2142

Publisher's Note Springer Nature remains neutral with regard to jurisdictional claims in published maps and institutional affiliations. 